\title{
Wetting and Surface Tension Measurements on Gold Alloys
}

\author{
Enrica Ricci and Rada Novakovic \\ National Research Council (CNR) - Institute of Physical Chemistry of Materials, \\ Via De Marini 6, I- 16149 Genoa (Italy) \\ E-mail:ricci@icfam.ge.cnr.it
}

Received: 5 June 2000

The surface tension and the density of some gold alloys have been measured and their wetting behaviour investigated in relation to different ceramic supports. Relationships between surface tension and density as a function of temperature are proposed.

The primary objective of jewellery production is the optimization of melting processes (1) and the choice of suitable ceramic materials for the crucibles is required, and this choice can be critical. Accordingly, there is a need for a range of materials with excellent thermal and mechanical properties to withstand high temperatures and, at the same time, resist attack by the molten metal, so that there is no metal-ceramic interaction $(2,3)$. To date, the materials used have been graphite, silicon carbide or the more common 'refractory materials', but there are still complaints about problems, principally related to the rapid consumption of the crucible, or pollution of the melt due to the detachment of particles from the crucible. A knowledge of the interaction between the ceramic and the liquid gold alloys can help in the definition of more suitable ceramic material for the melting processes used by goldsmiths. It is necessary to use materials that are highly resistant to wetting by metallic melts, thus a knowledge of the interface properties of liquid gold alloys in relation to ceramic materials is needed.

The interactions between the liquid metallic material and the ceramic are usually studied using:

1 Surface tension measurements of the liquid metal in contact with the ceramic material

2 Measurements of both surface tension and contact angle as a function of temperature

3 Surface tension measurements in the presence of liquid metal vapour.

Ott (4) has stated that there is insufficient data on the thermal properties of jewellery alloys in the liquid state and at solidification, including that on surface /interface tension. Surface tension is a thermophysical property that must be considered because it influences the surface structure of castings, and determines the interfacial interactions between melts and solid containers ( $i e$ interfacial tensions); and it is influenced by the presence of alloying elements such as zinc or silicon. Consequently, the study of its variation can provide useful information on the outcome of casting processes. We have therefore measured the surface tension and the density of some precious gold alloys as a function of temperature, and investigated their wetting behaviour on a number of relevant ceramic supports.

\section{THEORETICAL BACKGROUND}

For the sake of clarity, we provide some details on the nature of adhesion and wettability of liquid metals on solid substrates and the behaviour of surface tension.

\section{Wettability}

One of the basic equations which describes the behaviour of a liquid phase in contact with a solid surface is Young's equation (5):

$$
\sigma_{S V}=\sigma_{S L}+\sigma_{\mathrm{LV}} \cos \theta
$$

where $\sigma_{S V}, \sigma_{S L}, \sigma_{L V}$ are respectively the interface energies between the solid and the vapour phase, the solid and the liquid phase, and the liquid and the 
vapour phase; $\theta$ is the contact angle between the liquid and the solid phase (Figure 1). In wettability studies the work of adhesion $W_{A}$ is defined by Duprés equation (6), which can be written in both of the following two forms:

$$
\begin{gathered}
W_{A}=\sigma_{L V}+\sigma_{S V}-\sigma_{S L} \\
W_{A}=\sigma_{L V}(1+\cos \theta)
\end{gathered}
$$

From Equation (2), $W_{A}$ can be calculated by measuring the contact angle and the surface tension of the liquid.

From the studies of Naidich (6) it can be concluded that the wettability and adhesion are principally determined by two types of forces, $i e$ : physical interactions, especially dispersion and polarization forces, and chemical interactions. Physical interactions determine the wettability of low surface tension liquids (eg water, organic solutions, and hydrocarbons). Chemical wettability is characteristic of high temperature systems and generally shows a strong dependence on temperature. It would seem to be very easy to determine the contact angle $\theta$ but on the contrary, it is one of the quantities more difficult to measure with accuracy, especially in metal-ceramic systems. The scatter of the measurements is often very large, due to a number of factors. One of the more important is the roughness of the solid (ceramic) surface as emphasized by Wenzel (7). The actual value of the contact angle, $\theta^{*}$ can be correlated with the measured value through the relationship:

$$
\cos \theta^{*}=R \cos \theta
$$

where $R$ is the surface roughness coefficient. Moreover, the value of $\theta$ is different when determined in the 'advancing' stage compared with the 'retraction' stage. For example, when the surface roughness of alumina is about $R=1 \mu \mathrm{m}$, the molten lead on the alumina shows an advancing contact angle of $180^{\circ}$ while the

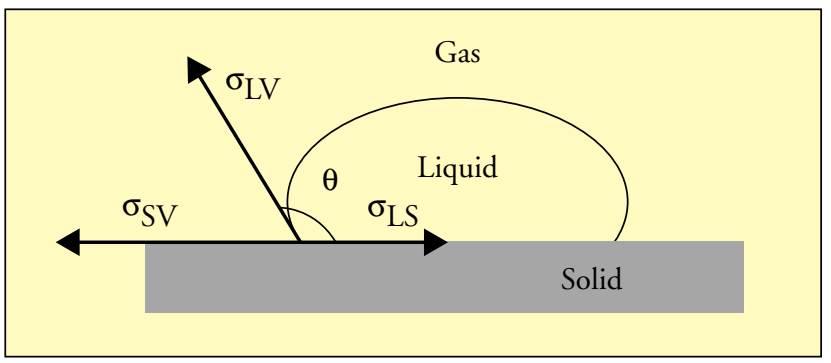

Figure 1 Interfacial parameters of a sessile drop retraction contact angle is $125^{\circ}$. The difference is drastically reduced if the roughness of the alumina is $R<0.03 \mu \mathrm{m}$. Moreover, many metals have high free oxidation energy that gives very low values of equilibrium pressure for oxide formation. Under unsuitable working conditions $(8,9)$, the formation of a thin film of oxide on the metallic surface inhibits 'actual' contact between the liquid metal and the ceramic (10).

In Table 1, the contact angle values are given for $\mathrm{Au}, \mathrm{Ag}, \mathrm{Cu}$, and $\mathrm{Zn}$, on graphite (11), vitreous silica (12 - 14), silicon carbide (15) and boron nitride (12). These types of ceramic materials, prevalently covalent, have a close electronic configuration with strong interatomic bonds, and were therefore chosen for evaluation as crucible materials for melting gold alloys. The principal components of the alloys: ie gold, silver and copper, do not exhibit a great affinity for these types of solids; in fact they have only weak physical interactions with solid covalent substrates (except copper on silicon carbide), as can be demonstrated by their contact angle and by the values of the corresponding work of adhesion, $W_{A}$.

\section{Surface Tension}

From the expressions for $W_{A}$, given in Equation 2, there is a strict correlation between wettability and surface tension. The surface tension of a fluid is a direct measure of the intermolecular forces acting at the surface and can be defined as the force per unit length acting parallel to the free surface. Data are sometimes expressed in terms of free surface energy, which is the free energy per unit area of surface. For pure liquids, the surface energy is numerically and dimensionally equal to the equivalent surface tension, $\sigma_{L V}$. The surface tension of pure molten metals depends on the strength of the cohesive forces acting between neighbouring atoms, and it can be related to other physicochemical properties of the material. The surface tension of molten metals tends to increase with increasing melting point and a correlation between surface tension and enthalpy of evaporation (16), compressibility, thermal expansion, etc, can be expected. The principal parameters affecting the surface tension are the chemical composition of the bulk phases and the temperature. The surface tension of any solvent can be drastically reduced by the presence of relatively low levels of certain solutes which are preferentially adsorbed at the surface. Such solutes are called 'surfaceactive' with respect to liquids. In general, for liquids the surface tension decreases with increasing temperature (ie negative temperature coefficient $\mathrm{d} \sigma / \mathrm{dT}$ ) going to 
Table 1 Wetting Parameters for Au, Ag and Cu on Different Substrates

\begin{tabular}{|c|c|}
\hline \multicolumn{2}{|c|}{ Substrate } \\
\hline C(Graphite) & $\begin{array}{l}\mathrm{Au} \\
\mathrm{Ag} \\
\mathrm{Cu}\end{array}$ \\
\hline $\mathrm{SiO}_{2}$ (Quartz) & $\begin{array}{l}\mathrm{Au} \\
\mathrm{Ag} \\
\mathrm{Cu}\end{array}$ \\
\hline SiC (sintered) & $\begin{array}{l}\mathrm{Au} \\
\mathrm{Ag} \\
\mathrm{Cu}\end{array}$ \\
\hline BN (cubic) & $\begin{array}{l}\mathrm{Au} \\
\mathrm{Ag} \\
\mathrm{Cu}\end{array}$ \\
\hline BN (hexagonal) & $\begin{array}{l}\mathrm{Au} \\
\mathrm{Ag} \\
\mathrm{Cu}\end{array}$ \\
\hline
\end{tabular}

$\begin{array}{ccc}\mathrm{T}\left[{ }^{\circ} \mathbf{C}\right] & \theta\left[{ }^{\circ}\right] & \mathbf{W}_{\mathbf{A}}[\mathbf{~ m N}] \\ - & - & - \\ 980 & 136 & 255 \\ 1100 & 140 & 315 \\ 1500 & 142 & 20 \\ 1373 & 140 & 246 \\ 1353 & 143 & 227 \\ 1373 & 142 & 174 \\ 1423 & 128 & 474 \\ 1063 & 148 & - \\ 960 & 127 & - \\ 1083 & 138 & - \\ 1100 & 145 & 175 \\ 1000 & 146 & 160 \\ 1100 & 137 & 360 \\ - & - & - \\ 1000 & 140 & 200 \\ 1100 & 146 & 225\end{array}$

zero at the critical point: the variation often follows a linear function law over a limited temperature range:

$$
\sigma[\mathrm{mN} / \mathrm{m}]=\sigma^{\circ}[\mathrm{mN} / \mathrm{m}]-\mathrm{d} \sigma / \mathrm{dT}\left(\mathrm{T}-\mathrm{T}_{\mathrm{m}}\right)
$$

Despite its technological relevance, the temperature coefficient of pure liquid metals is known to an accuracy of only about $\pm 50 \%$, whereas the surface tension is known to an accuracy of about $\pm 5 \%$ (17). This property is almost completely unknown for most alloys, in particular for multicomponent industrial alloys, due to the experimental difficulties involved, so that very few data on the surface tension of complex alloys measured at high temperature are available in the literature, and data are often obtained by applying model calculations (18).

An overview of surface tension data of pure liquid metals has recently been published (19). All available values of experimental surface tension literature data and the temperature coefficients $(\mathrm{d} \sigma / \mathrm{dT})$ for each pure metal are reported, taking into account the type of metal, its reactivity, the experimental procedure used, the atmosphere composition used when determining the surface tension, the temperature range and the oxygen concentration present in the melt as the main impurity. The surface tension values of liquid $\mathrm{Au}, \mathrm{Ag}$, $\mathrm{Cu}$ and $\mathrm{Zn}$ reported previously (19) are given in Table 2 , with the relationship of their densities to temperature, as determined by Lucas (20).

\section{THE GOLD ALLOYS: AU-AG-CU AND AU-AG-CU-ZN}

As mentioned previously, the contact angle $\theta$ is difficult to measure, especially in liquid metal-ceramic systems, and the scatter of measurements is often very large. The same trend has been observed for the surface tension measurements (21). As stated previously, some values of contact angles, surface tension and density of pure metals are available in the literature, but others have yet to be determined. The situation is worst for the alloys: there is only very limited original experimental data available on their surface properties measured at high temperature (22 24 ), and predictions of density and surface tension of ternary or more complex alloys need to be based on them. An estimate of liquid alloy density at a given temperature can be obtained from the molecular weight and the molar volume of its components obtained from the ideal solution model (25). In the same way, the calculation of surface tension of liquid alloys can be performed, based on solution models and phase diagram data. In the literature, the surface tension isotherm of liquid $\mathrm{Au}-\mathrm{Ag}-\mathrm{Cu}$ alloys has been developed using perfect and regular solution models $(23,26,27)$. Both descriptions involve the input of thermodynamic parameters of the ternary $\mathrm{Au}-\mathrm{Ag}-\mathrm{Cu}$ system, its binary subsystems ( $\mathrm{Au}-\mathrm{Ag}, \mathrm{Au}-\mathrm{Cu}$ and $\mathrm{Ag}-$ $\mathrm{Cu}$ ) and its pure components and their surface tension 
Table 2 Surface Tension and Temperature Coefficient at the Melting Temperature and Temperature-Density Dependence of Au, Ag, $C u$ and $Z n$

$\begin{array}{ccc}\begin{array}{c}\text { Pure } \\ \text { metal }\end{array} & \begin{array}{c}\mathbf{T}_{m} \\ {\left[{ }^{\circ} \mathbf{C}\right]}\end{array} & \begin{array}{c}\text { Density }{ }^{[20]}(\rho) \\ {\left[\mathrm{g} / \mathrm{cm}^{3}\right]}\end{array} \\ \mathrm{Au} & 1063 & \frac{17.31-13.43 \cdot 10^{-4}\left(T-T_{m}\right)}{0.1073+8.27 \cdot 10^{-6}\left(T-T_{m}\right)} \\ \mathrm{Ag} & 961 & \frac{1}{0.1260+12.1 \cdot 10^{-6}\left(T-T_{m}\right)} \\ \mathrm{Cu} & 1084 & \frac{1}{0.15205+27 \cdot 10^{-6}\left(T-T_{m}\right)} \\ \mathrm{Zn} & 420 & \end{array}$

$\begin{array}{cc}\begin{array}{c}\text { Surface tension } \\ \left(\sigma\left(\mathbf{T}_{\mathbf{m}}\right)\right) \\ {[\mathrm{mN} / \mathrm{m}]}\end{array} & \begin{array}{c}\mathbf{d} \sigma / \mathbf{d T} \\ {\left[\mathrm{mN} / \mathbf{m}^{\circ} \cdot \mathbf{C}^{-1}\right]}\end{array} \\ 1138 & -0.19 \\ 910 & -0.17 \\ 1355 & -0.19 \\ 815 & -0.25\end{array}$

data. According to data reported by Gallois et al (23), the perfect solution model has been applied to a mathematical representation of surface tension isotherms of ternary gold alloys (Figure 2).

As is well known, the properties of the $\mathrm{Au}-\mathrm{Ag}-\mathrm{Cu}$ alloys with average silver content, ie those in the plateau of the miscibility gap, can be improved by adding zinc, which acts as a deoxidant during the melting process, lowers the melting points and tends to reduce the melting ranges of these alloys, so the quaternary $\mathrm{Au}-\mathrm{Ag}-\mathrm{Cu}-\mathrm{Zn}$ gold alloys are usually used in jewellery casting. It is not yet possible to compare the calculations of surface tension of quaternary Au$\mathrm{Ag}-\mathrm{Cu}-\mathrm{Zn}$ gold alloys in the same manner as has been done for ternary alloys, due to the complexity

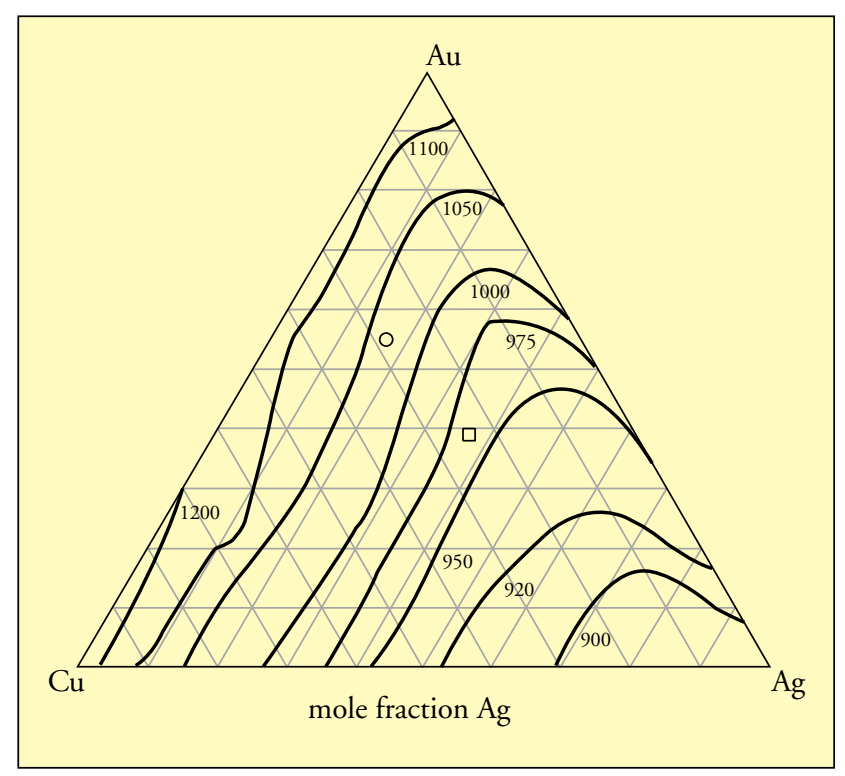

Figure 2 Iso surface tension lines of the $A u-A g$-Cu system (23) and surface tension experimental values of 'Au14' $(\square)$ and $\mathrm{Au} 18(\mathrm{O})$ alloys at $T=1108^{\circ} \mathrm{C}$ of the thermodynamic models, that need data from all subsystems, and the lack of experimental data. Consequently, an estimation of their surface tensions can be made only with respect to the influence of zinc on this property: zinc reduces the surface tension of gold alloys. In fact, high zinc losses from the alloy have been observed during melting, due to the high vapour pressure of this metal and its high affinity for oxygen $(28,29)$. Thus the surface tension values of quaternary gold alloys should be lower than those of ternary gold alloys having the same gold content.

\section{EXPERIMENTAL}

\section{Methodology}

The contact angle and the surface tension of some precious gold alloys were measured by the sessile drop technique (30). The sessile drop method conventionally used to determine the surface properties of liquid metals at high temperature was chosen because it is particularly suitable for systems whose contact angle is greater than $90^{\circ}$ and because it allows the surface tension and the contact angle to be measured simultaneously.

The sessile drop method is based on the measure of the drop shape which is the result of the equilibrium between the action of the gravitational field, which tends to flatten the drop, and that of surface tension which requires the smallest surface area. It is described by Laplace's equation, which relates the excess pressure $\Delta P$ at a curved surface or interface, with the principal radii of curvature, $r_{1}$ and $r_{2}$, at a point on the surface:

$$
\Delta \mathrm{P}=\sigma\left[\frac{1}{r_{1}}+\frac{1}{r_{2}}\right]
$$


Laplace's equation can be rewritten in the more explicit form, as proposed by Bashforth and Adams (31):

$$
2+\frac{\beta z}{b}=\left[\frac{1}{(R / b)}+\frac{\sin \phi}{(x / b)}\right]
$$

where $\beta=\frac{p g b^{2}}{\sigma}, b$ is the radius of curvature at the drop apex, $\mathrm{R}$ is the radius of curvature and $\phi$ is the inclination of the tangent at the point $(x, z)(32)$. This equation does not have analytical solutions, so the parameters that appear in it, in particular the surface tension, should be determined numerically, ie by fitting this equation to the experimental drop shape. The measured parameters are the equatorial diameter and the distance between the equatorial plane and the drop apex. In the last 100 years, the sessile drop method has attracted the attention of a large number of scientists, who have concentrated their research in two areas: the numerical solution of Equation 7 and the presentation of results in the form of handy reference tables (33). The aim is to improve the methods for measuring the shape of the drop with the highest possible precision and to design an experimental set-up which could guarantee extremely clean and controlled physical-chemical conditions.

Computerized numerical calculations as well as image analysis techniques are currently being developed $(34,35)$, making the sessile drop method more reliable, more accurate and thus attractive for surface properties measurements. This method is particularly suitable for high temperature systems but it requires a knowledge of the real drop dimensions in the micron range, a perfect axial symmetry of the drop and extensive experimental precautions. The experimental apparatus must be used under controlled environmental conditions, ie a controlled working atmosphere: high vacuum or inert gas, very low oxygen content or monitored oxygen partial pressure using a specific solid state oxygen sensor.

\section{Materials and Procedures}

Surface tension and contact angle measurements were made in a horizontal furnace which is heated by an $800 \mathrm{MHz}$ high-frequency generator coupled to a graphite heater and thermal shields. The measurements were performed under an argon atmosphere $\left(\mathrm{O}_{2}<\right.$ $0.1 \mathrm{ppm})$. The temperature was measured using a $\mathrm{Pt} / \mathrm{Pt}-\mathrm{Rh}$ thermocouple placed inside a small hole drilled in the graphite support just below the specimen, and had an accuracy of $\pm 1^{\circ} \mathrm{C}$. Samples of gold (99.9999\%, Marz-grade) and its standard alloys (commercial-grade) were pre-melted under a vacuum $\left(\mathrm{P}=3 \times 10^{-5} \mathrm{mbar}\right)$ at about $50^{\circ} \mathrm{C}$ above the melting temperature. For the contact angle measurements a pre-melted drop $(\sim 1 \mathrm{~g})$ was placed on the substrate plate and then inserted into the furnace so that the true advancing angles could be measured. Resting on a perfectly level substrate, the drop was illuminated by an aligned light source and photographed using a highresolution film. The contact angle was read with a metrological optical microscope with a resolution of $\pm 1^{\circ}$. Surface tension was measured in the same apparatus putting the pre-melted alloy sample of about $4.5 \mathrm{~g}$ in a sapphire cup especially designed to assure the

Table 3 Compositions of Gold Alloys Used in this Work and their Melting Range and Liquidus Temperatures

\begin{tabular}{|c|c|c|c|c|c|c|}
\hline \multirow{2}{*}{$\begin{array}{l}\text { Alloy } \\
\text { 'Aul8' }\end{array}$} & \multicolumn{3}{|c|}{ Composition } & \multicolumn{2}{|c|}{$\begin{array}{c}\text { Melting temperature range } \\
\left.{ }^{\circ} \mathrm{C}\right]\end{array}$} & \multirow{2}{*}{$\begin{array}{c}\text { Liquidus } \\
\text { temperature }\left[{ }^{\circ} \mathrm{C}\right] \\
893\end{array}$} \\
\hline & $\begin{array}{l}\mathrm{Au} \\
\mathrm{Ag} \\
\mathrm{Cu}\end{array}$ & $\begin{array}{l}75.0 \\
12.5 \\
12.5\end{array}$ & $\begin{array}{l}54.92 \\
16.71 \\
28.37\end{array}$ & 892 & 918 & \\
\hline ‘Aul8/Zn’' & $\begin{array}{l}\mathrm{Au} \\
\mathrm{Ag} \\
\mathrm{Cu} \\
\mathrm{Zn}\end{array}$ & $\begin{array}{l}75.0 \\
11.5 \\
11.5 \\
2.0\end{array}$ & $\begin{array}{l}54.48 \\
15.25 \\
25.89 \\
4.380\end{array}$ & 866 & 896 & 868 \\
\hline 'Aul4’ & $\begin{array}{l}\mathrm{Au} \\
\mathrm{Ag} \\
\mathrm{Cu}\end{array}$ & $\begin{array}{l}58.5 \\
30.0 \\
11.5\end{array}$ & $\begin{array}{l}39.28 \\
36.78 \\
23.94\end{array}$ & 859 & 902 & 882 \\
\hline 'Aul 4/Zn' & $\begin{array}{l}\mathrm{Au} \\
\mathrm{Ag} \\
\mathrm{Cu} \\
\mathrm{Zn}\end{array}$ & $\begin{array}{l}58.5 \\
22.0 \\
11.5 \\
8.0\end{array}$ & $\begin{array}{l}36.93 \\
25.36 \\
22.50 \\
15.2 \mid\end{array}$ & 773 & 806 & 775 \\
\hline
\end{tabular}


Table 4 Contact Angles of Gold and its Alloys Measured on Different Substrates

\begin{tabular}{|c|c|c|c|c|c|c|c|c|}
\hline \multirow[t]{2}{*}{ Substrate } & \multirow{2}{*}{$\begin{array}{c}\mathbf{R}_{\mathbf{a}} \\
{[\mu \mathbf{m}]}\end{array}$} & \multirow{2}{*}{$\begin{array}{r}\theta\left[^{\circ}\right] \mathrm{Au} \\
\mathrm{T}=1080^{\circ} \mathrm{C}\end{array}$} & \multicolumn{2}{|c|}{$\theta\left[^{\circ}\right]^{\prime} \mathrm{Au} / \mathrm{B}^{\prime}$} & \multicolumn{2}{|c|}{$\theta\left[^{\circ}\right]^{\prime} \mathrm{Au} / \mathrm{8} / \mathrm{Zn}$ ' } & \multicolumn{2}{|c|}{$\theta\left[^{\circ}\right]^{\prime A u l 4}$} \\
\hline & & & $\mathrm{T}=930^{\circ} \mathrm{C}$ & $\mathrm{T}=1080^{\circ} \mathrm{C}$ & $\mathrm{T}=930^{\circ} \mathrm{C}$ & $\mathrm{T}=1080^{\circ} \mathrm{C}$ & $\mathrm{T}=930^{\circ} \mathrm{C}$ & $\mathrm{T}=1080^{\circ} \mathrm{C}$ \\
\hline$C_{\text {graph }}$ & $<0.20$ & $154 \pm 2$ & $139 \pm 3$ & $139 \pm 2$ & $142 \pm 2$ & $143 \pm 2$ & $|5| \pm 2$ & $145 \pm 1.5$ \\
\hline VC & $<0.20$ & $|4| \pm 2$ & $148 \pm 3$ & $148 \pm 2$ & $152 \pm 3$ & $153 \pm 2$ & $164 \pm 2$ & $150 \pm 2$ \\
\hline $\mathrm{SiO}_{2^{-} \mathrm{qz}}$ & $<0.01$ & $133 \pm 2$ & $140 \pm 1$ & $140 \pm 3$ & $149 \pm 2$ & $148 \pm 3$ & $132 \pm 1$ & $134 \pm 1$ \\
\hline $\mathrm{SiC}_{\text {sinter }}$ & $<0.30$ & $144 \pm 4$ & $147 \pm 2$ & $164 \pm 4$ & $150 \pm 1$ & $145 \pm 3$ & $148 \pm 2$ & $140 \pm 1$ \\
\hline$B N_{\text {hexag }}$ & $<0.20$ & $|4| \pm 2$ & $156 \pm 3$ & $153 \pm 3$ & $142 \pm 2$ & $|4| \pm 3$ & $162 \pm 2$ & $159 \pm 2$ \\
\hline
\end{tabular}

best axis-symmetric conditions. A fast automatic acquisition procedure (ASTRA ${ }^{\mathrm{R}}$ ) (35) was used to acquire the drop profile, giving the surface tension data with an accuracy $<0.1 \%$. The alloy densities were also determined in this way, from their weight and their measured volume at each temperature.

The compositions of gold alloys measured in this work, and identified in the text as 'Au18', 'Au14', 'Au $18 / \mathrm{Zn}$ ', and 'Au14/Zn' are given in Table 3, with their melting range temperature values and the corresponding 'liquidus' temperatures as determined by differential thermal analysis (DTA). The contact angles of gold and of its alloys were measured under an argon atmosphere on commercial graphite (C), vitreous carbon $(\mathrm{VC})$, vitreous silica $\left(\mathrm{SiO}_{2}\right.$-quartz), sintered silicon carbide $(\mathrm{SiC})$ and boron nitride (BNhexagonal), to verify whether these materials could be interesting alternatives to those commonly used as crucibles or containers in melting/casting processes. The ceramic materials employed (commercial graphite, vitreous carbon, vitreous silica, sintered silicon carbide and boron nitride) were in the form of plates of $15 \mathrm{~mm}$ diameter and $2 \mathrm{~mm}$ thickness, or blocks $(15 \times 15 \times 2 \mathrm{~mm})$. They were ultrasonically and chemically cleaned, then heated for $30 \mathrm{~min}$ at $\mathrm{T}>1100^{\circ} \mathrm{C}$. They were then polished consecutively with 1200-, 2400- and 4000-grade silicon carbide paper. The roughness of the substrates was measured after polishing with a roughness meter with a vertical resolution of $0.01 \mu \mathrm{m}$. The average height of asperity of the plates is expressed with a roughness factor, $R_{a}$ and shown in Table 4.

\section{RESULTS AND DISCUSSION}

\section{Contact Angle}

The contact angle values $(\theta)$ of pure gold and its alloys were measured at two different temperatures (Table 4), and they are higher than $130^{\circ}$, as clearly shown in

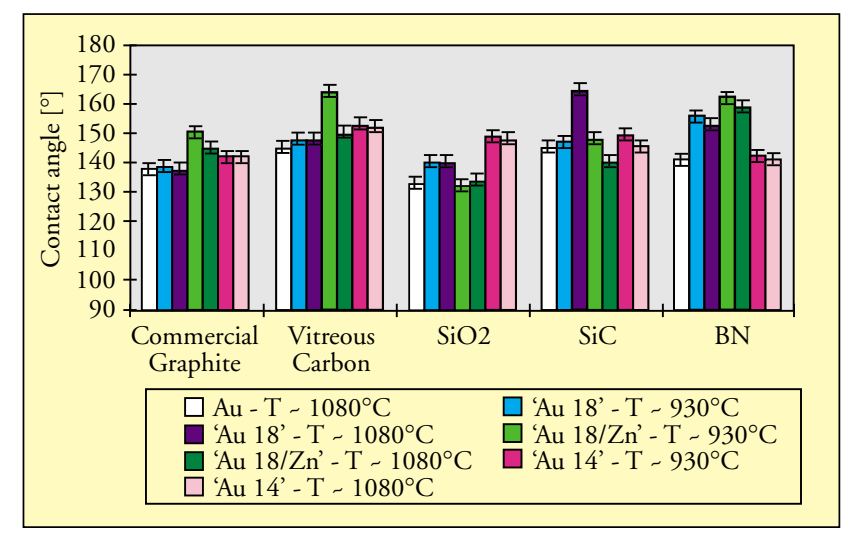

Figure 3 Contact angle values of gold and precious gold alloys measured on different ceramic materials at $T=930^{\circ}$ and $T=1080^{\circ} \mathrm{C}$ under pure argon

Figure 3. The contact angles of the 'Au18' alloy, measured at $930^{\circ} \mathrm{C}$ and $1080^{\circ} \mathrm{C}$ are not significantly different from each other. Quite similar behaviour is found for the 'Au14' and the 'Au18/Zn' alloys. This means that, under the conditions used, the interaction between the metallic and the ceramic materials is negligible and no chemical reaction occurs at the interface. However, the contact angle value obtained for the 'Au18' alloy on silicon carbide at $1080^{\circ} \mathrm{C}$ is higher $\left(164^{\circ}\right)$ than the value obtained at $930^{\circ} \mathrm{C}\left(147^{\circ}\right)$. The contact angle values measured on $\mathrm{SiC}$ and on $\mathrm{BN}$ are slightly greater than those measured on the other ceramic materials, and indicate the lower adhesion force between melt and substrate.

\section{Density}

The measured density values of the alloys were determined for those used for the surface tension measurements, and in the same temperature range. The standard deviation of each isothermal set of measurements was about $0.03 \mathrm{~g} / \mathrm{cm}^{3}$. The variation of density with temperature for the alloys: 'Au18', 'Au18/Zn' and 'Au14' are shown in Figure 4. It should be noted that the presence of $\mathrm{Zn}(2.0 \mathrm{wt} \%)$ in the 


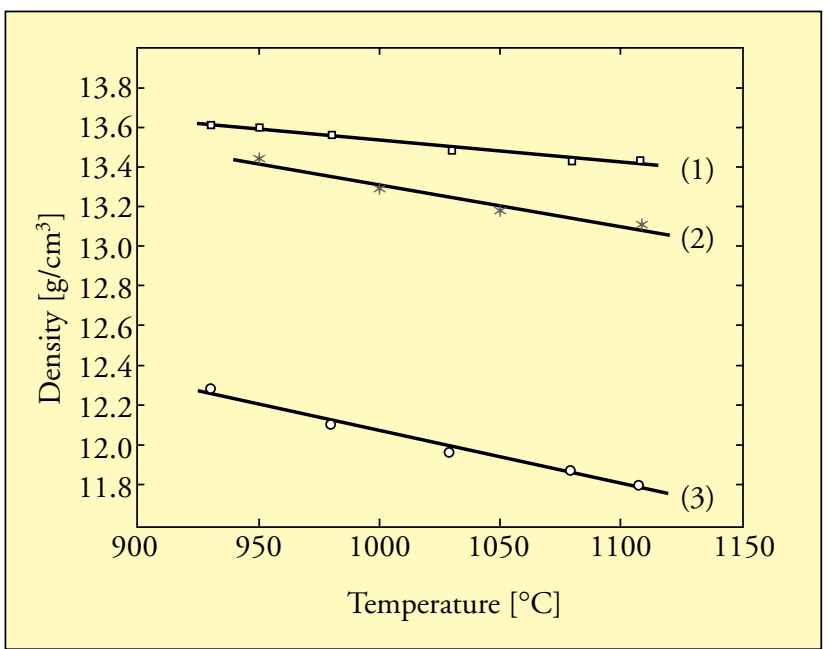

Figure 4 Density of the gold alloys as a function of temperature [(1) - 'Au18'; (2) - 'Au18/Zn'; (3) - 'Au14']

quaternary 'Au18/Zn' alloy, decreased the density with respect to the ternary 'Au18' alloy having the same gold content. The same behaviour was noted for the 'Au14/Zn' alloy in relation to the 'Au14' alloy, in which this element is present at $8.0 \mathrm{wt} \%$. Due to very high volatility induced by the presence of $\mathrm{Zn}$ only two measurements were possible at low temperature.

Applying the linear regression to the results in Table 5, the relationships between density and temperature are obtained, and are expressed as follows:

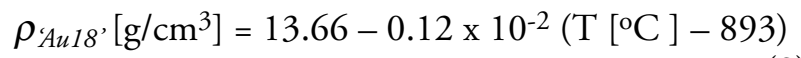

$$
\begin{aligned}
& \rho_{A u 18 / Z n^{\prime}}=13.59-0.21 \times 10^{-2}(\mathrm{~T}-868) \\
& \rho_{\text {'Au14 }}=12.39-0.26 \times 10^{-2}(\mathrm{~T}-882)
\end{aligned}
$$

\section{Surface Tension}

The surface tension of the precious gold alloys was measured by the sessile drop method under an argon atmosphere at different temperatures. Each surface tension and density value (Table 5) reported for the given temperature is the average of a large number of measurements performed under isothermal conditions, maintained at least for $15 \mathrm{~min}$, so that they can be assumed to be close to equilibrium. In each isothermal zone, the measured surface tension showed a standard deviation of about $5 \mathrm{mN} / \mathrm{m}$ around the reported mean value. The surface tension of the ternary 'Au18' and 'Au14' alloys, obtained at $\mathrm{T}=1108^{\circ} \mathrm{C}$, have been represented on the $\mathrm{Au}-\mathrm{Ag}-\mathrm{Cu}$ isothermal section (Figure 2) together with iso-surface tension lines at $\mathrm{T}=1108^{\circ} \mathrm{C}$, as calculated following Gallois et al. The measured values for surface tension of the 'Au18' and 'Au14' alloys are respectively $\sigma=1044 \mathrm{mN} / \mathrm{m}$ and $\sigma=965 \mathrm{mN} / \mathrm{m}$ and the corresponding points lie on the diagram between the iso-surface tension lines which represent the surface tension values of 1025 $\mathrm{mN} / \mathrm{m}$ and $1050 \mathrm{mN} / \mathrm{m}$ and between those which represent the surface tension values of $950 \mathrm{mN} / \mathrm{m}$ and $975 \mathrm{mN} / \mathrm{m}$.

As already mentioned, only two measurements were performed for the alloy 'Au14/Zn' due to the very high volatility of $\mathrm{Zn}$. The surface tension behaviour of the gold alloys between $930^{\circ} \mathrm{C}$ and $1108^{\circ} \mathrm{C}$ is shown as a function of temperature in Figure 5. The temperature

Table 5 Experimental Density and Surface Tension Values of Gold Alloys Measured between 830 and $1108^{\circ} \mathrm{C}$ under an Argon Atmosphere

\begin{tabular}{ccc} 
Temperature & \multicolumn{3}{c}{ 'Au l 8' } \\
{$\left[{ }^{\circ} \mathrm{C}\right]$} & $\rho\left[\mathrm{g} / \mathrm{cm}^{3}\right]$ & $\sigma[\mathrm{mN} / \mathbf{m}]$ \\
830 & - & - \\
930 & 13.61 & 1064 \\
950 & 13.60 & 1065 \\
980 & 13.57 & 1067 \\
1000 & - & - \\
1030 & 13.49 & 1054 \\
1050 & - & - \\
1080 & 13.44 & 1047 \\
1108 & 13.43 & 1044
\end{tabular}

'Au I 8/Zn'

$\begin{array}{cc}\rho\left[\mathrm{g} / \mathrm{cm}^{3}\right] & \sigma[\mathrm{mN} / \mathbf{m}] \\ - & - \\ - & - \\ 13.43 & 984 \\ - & - \\ 13.30 & 1005 \\ - & - \\ 13.20 & 1027 \\ - & - \\ 13.10 & 1033\end{array}$

'Aul4'

$\begin{array}{cc}\rho\left[\mathrm{g} / \mathrm{cm}^{3}\right] & \sigma[\mathrm{mN} / \mathrm{m}] \\ - & - \\ 12.29 & 999 \\ - & - \\ 12.11 & 996 \\ - & - \\ 11.97 & 989 \\ - & - \\ 11.88 & 973 \\ 11.81 & 965\end{array}$

'Au l 4/Zn'

$\begin{array}{cc}\rho\left[\mathrm{g} / \mathrm{cm}^{3}\right] & \sigma[\mathrm{mN} / \mathrm{m}] \\ \mid \mathrm{II.9|} & 97 \mid \\ \mid \mathrm{I} .88 & 962 \\ - & - \\ - & - \\ - & - \\ & - \\ - & - \\ - & -\end{array}$




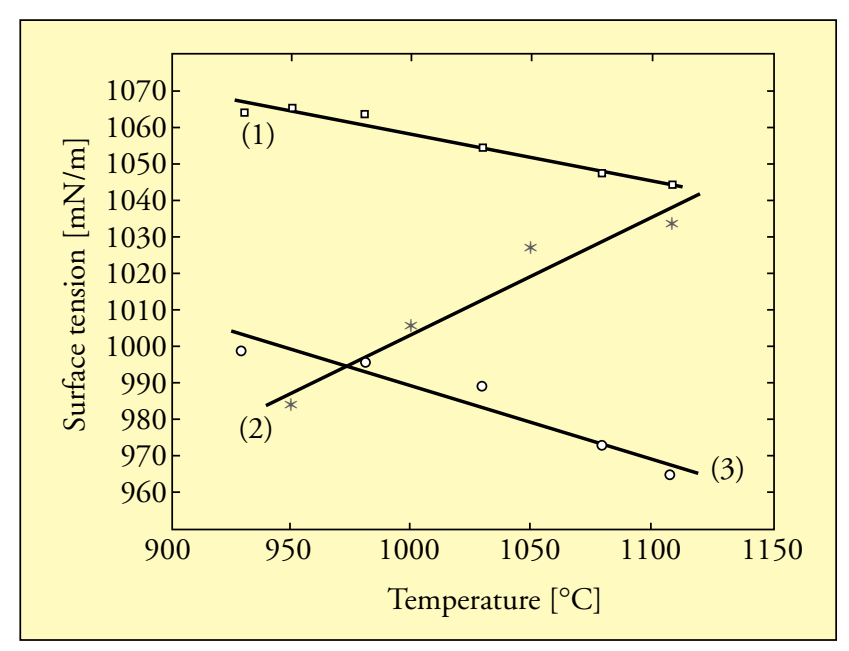

Figure 5 Surface tension of the gold alloys as a function of temperature [(1) - 'Au18'; (2) - 'Au18/Zn'; (3) 'Au14']

dependence of the gold alloys 'Au18' and 'Au14' can be expressed by the following equations referring to the liquidus temperature:

$$
\begin{aligned}
& \text { 'Au 18’: } \sigma[\mathrm{mN} / \mathrm{m}]=1071.3-0.124(\mathrm{~T}-893) \\
& \text { ‘Au 14’: } \sigma[\mathrm{mN} / \mathrm{m}]=1013-0.196(\mathrm{~T}-882)
\end{aligned}
$$

The standard deviation is less then $1 \%$. On the other hand, the surface tension of the 'Au18/Zn' alloy in the temperature range between $930^{\circ} \mathrm{C}$ and $1108^{\circ} \mathrm{C}$, shows a standard deviation of about $2 \%$. The surface tension values of this alloy, containing $2 \mathrm{wt} \%$ of $\mathrm{Zn}$, are lower than those of the 'Au18' alloy with the same gold content, due to the tensio-active effect of the $\mathrm{Zn}$. At higher temperatures, the influence of evaporation effects on the surface tension behaviour is more pronounced: the alloy loses the zinc due to the high volatility of this element and tends to reach the corresponding surface tension value pertaining to the alloy with the same gold content but without zinc. As each set of surface tension measurements for each given temperature was performed under isothermal conditions and maintained for several minutes, no variations in surface tension were observed during each step; but an increase in surface tension over temperature is observed and as a consequence a positive value $(+0.322)$ of the temperature coefficient $(\mathrm{d} \sigma / \mathrm{dT})$ is obtained. This increase is due to the effect of the $\mathrm{Zn}$, without any kinetic contribution. On the other hand, in the case of the 'Au14/Zn' alloy having 8 wt $\%$ of $\mathrm{Zn}$, our experimental data showed a decrease in surface tension, confirming the tensio-active effect of this element : the difference of the surface tension values for two alloys with the same gold content but with different amounts of zinc, was about $30 \mathrm{mN} / \mathrm{m}$ at $930^{\circ} \mathrm{C}$. Above this temperature, the evaporation effects made further measurements impossible. The different behaviour of 'Au18/Zn' and 'Au14/Zn' alloys can also be interpreted by taking into account the larger zinc concentration in the 'Au14/Zn' alloy, which allows a sufficient surface zinc concentration to be maintained with a consequent low value for the surface tension.

\section{CONCLUSIONS}

The wetting behaviour of some typical liquid $\mathrm{Au}-\mathrm{Ag}$ $\mathrm{Cu}$ alloys has been studied and their contact angles on some ceramic materials determined. All of the contact angles are higher than $130^{\circ}$ : this means that, under the conditions used, the interactions between the metallic and ceramic materials are negligible and that no chemical reaction occurs at the interface. The comparison of contact angle values, measured on ceramic samples of the same surface roughness, indicates that there are no strong differences between pure gold and its alloys. An exception is represented by the contact angles of the alloys measured on $\mathrm{SiC}$ and $\mathrm{BN}$ under argon, which reveal a slightly lower adhesion in these cases. Consequently, from viewpoint of wettability, all the ceramics investigated seem to be suitable for use as crucible materials in goldsmith melting processes, with perhaps a slight preference for $\mathrm{SiC}$ and $\mathrm{BN}$, taking into account their mechanical properties. Moreover, the variation of surface tension of the 'Au18' and 'Au14' gold alloys as a function of temperature under an argon atmosphere can be accurately represented by the Equations 11 and 12, and the density values determined during the same experiments show a good correlation. In spite of the fact that the density shows a good correlation, the surface tension of the 'Au18/Zn' alloy behaves differently and shows a positive temperature coefficient due to the presence of $\mathrm{Zn}$.

On the basis of the experimental results obtained in this work, some basic tools are now available to assist in correctly performing melting processes used by goldsmiths. The melting processes should be performed under rigidly controlled environmental conditions: ie pure argon or inert atmosphere, high quality basic materials, accurate temperature control. However, further accurate measurements of thermophysical properties such as surface tension, 
density, viscosity, heat of solidification, and thermal conductivity are needed for a large number of gold alloys to better characterize the melting/casting processes used in the jewellery industry.

\section{ACKNOWLEDGEMENT}

This research was supported by the project 'PRO Art: Research Program in Support of Craft Goldsmith Production and Trade' of CNR-MICA, Italy.

\section{ABOUT THE AUTHORS}

Enrica Ricci is a researcher at the Institute of Physical Chemistry of Materials (ICFAM) Genoa of the National Research Council of Italy (CNR). Since 1987 she has been in charge of the research project: 'Surface Properties of Liquid Metals and Alloys'. She is the author and co-author of more than 40 scientific papers.

Rada Novakovic has qualifications in materials science and thermodynamics. Her main research interests are mathematical modelling of physicochemical processes and thermodynamics. Since 1993 she has been working in Italy; from 1996 to the present at the Institute of Physical Chemistry of Materials (ICFAM) Genoa of the National Research Council of Italy (CNR).

\section{REFERENCES}

1 W.S. Rapson and T. Groenewald, in 'Gold Usage', ed. Academic Press. Inc., New York, 1978

2 L. Lay, in 'Corrosion Resistance of Technical Ceramics', ed. HMSO Public. Centre, London, 1991

3 F.L. Riley, 'Proceedings: Key Engineering Materials Corrosion of Advanced Ceramics, 1996, 113

4 D. Ott, Gold Bull., 2000, 33, 25
5

6 Y.V. Naidich, in 'Progress in Surface and Membrane Science, ed. D.A. Cadenhe and J.F. Danielli, Academic Press Inc., New York, 1981

7 R.N. Wenzel, J. Phys. Chem., 1949, 53, 1466

8 N. Eustathopoulos and J.C. Joud, in 'Current Topics in Material Science', ed. E. Kaldis, North Holland Publ., 1980, 4, 281

9 E. Ricci, A. Passerone and J.C. Joud, Surf. Sci., 1988, 206, 533

10 I. Rivollet, D. Chatain and N. Eustathopoulos, Acta Metall., 1987, 35, 835

11 Y.V. Naidich, V.M. Perevertajlo and G.M.Y. Nevodinik, Poroshk. Metallurg., 1972, 7, 51

12 Y.V. Naidich, 'Kontaktnie Javlenia v Metallicheskih Rasplavah', Naukova Dumka, Kiev, 1972

13 R. Sangiorgi, M.L. Muolo and A. Passerone, Rev. Int. Hautes Temp. Refract., 1985, 22, p. 175

14 R. Sangiorgi, M.L. Muolo, D. Chatain and N. Eustathopoulos, J. Am. Ceram. Soc., $1988,71,742$

15 S. Takahashi and O. Kuboi, J. Mater. Sci., 1996, 31, p.1797

16 A.S. Skapski, J. Chem. Phys., 1948, 16, 389

17 N. Eustathopoulos, B. Drevet and E. Ricci, J. Crystal Growth, 1998, 191, 268

18 T. Tanaka, K. Hach and S. Hara, MRS Bull., April 1999, p.45

19 N. Eustatopoulos, E. Ricci and B. Drevet, 'Techniques de L'ingenieur', 1999, M67-3

20 L.D. Lucas, Mem. Sci. Rev. Met., 1964, 61, 1; ie 1972, 69, 395

21 B.J. Keene, Int. Materials Rev., 1997, 38, 157

22 M.M.A. Bricard, N. Eustathopoulos, J.C. Joud and P. Desré, C.R. Acad.Sc.Paris, 1973, 276

23 B. Gallois and C.H.P. Lupis, Metall. Trans. B, 1981, 12B, 679

24 V.V. Polujanskaja and Y.V. Naidich, 'Proc. High Temp. Capillarity Intern. Conf. Bratislava (SK)', 1994, p.271

25 T. Iida and R.I.L. Guthrie, in 'The Physical Properties of Liquid Metals', Clarendon Press, Oxford, 1993

26 M. Guttmann, Surf. Sci., 1975, 53, 213

27 H.K. Lee, J.P. Hajra and M.G. Frohberg, Z.Metallkd., 1992, 83, p.8

28 C.J. Raub and D. Ott, Gold Bull., 1983, 16, 46

29 K. Nogi, K. Ogino, A. McLean and W.A. Miller, Metall.Trans.B, 1986, 17B, 163

30 J. Padday, in 'Surface and Colloid Science', ed, E.Matijevic, Wiley Publ., 1969, 1, 101

31 F. Bashforth and J.C. Adams, 'An attempt to Test the Theories of Capillary Actions', Cambridge University Press, 1883

32 A. Passerone and E. Ricci, in 'High Temperature Tensiometry Drops and Bubbles in Interfacial Research', ed. D.Möbius and R.Miller, Elsevier Sci., 1998, p. 475

33 N.E Dorsey, J. Wash. Acad. Sci., 1928, 18, 505

34 C. Maze and G. Burnet, Surf. Sci., 1969, 13, 451; 1971, 24, 335

35 L. Liggieri and A. Passerone, High Temp. Techn., 1989, 7, 80

\section{EUROPACATV}

\section{5th European Congress on Catalysis}

\section{Symposium on Gold and Silver Catalysis University of Limerick, Ireland, 2- 7 September, 2001}

\footnotetext{
One of the eighteen Symposia planned for this Conference is on 'Catalysis by Gold and Silver'. It is being convened and chaired by Dr David Thompson : Fax: +44 118984 5717; E-mail: DTThompson@aol.com) and Prof dr ir Leon Lefferts (University of Twente, The Netherlands) : Fax: +31 53 4894683; E-mail: 1.lefferts@ct.utwente.nl : see also inside front cover of this issue.

If you are interested in finding out more about any other aspects of the programme contact:

EuropacatV, University of Limerick, Limerick, Ireland Tel: +353 61202641 Fax: +353 61202602

E-mail: europacatv@ul.ie Website: http://www.ul.ie/-cer/EuropaCatV.html
} 